Theories \& Applications, the International Edition

Printed Version: (ISSN 2090-5262)

Online Version: (ISSN 2090-5270)

November 2012, Volume 2, No. 3 Pages (31 - 47)

\title{
Building an Evaluation Model in the Light of the Mechanical Profile of Back- Telna-Back Skill in Rhythmic Gymnastics
}

\author{
Suzan Salah Eldin Tantawy*
}

\begin{abstract}
:
Studying the kinematics of sports performance is one of the most complicated problems and this can be referred to the difficulty of controlling these variables the influencing factors. This study aims for building an evaluation model for back-telna-back skill in the light of the biomechanical profile. The research was applied on a sample of distinguished rhythmic gymnastics players $(N=6)$ performing at the international level. Anthropometric and physical measurements were taken in addition to evaluating the level of performing the skill of back-telna-back. Kinematicographic analysis was applied on the recorded trials to obtain the most effective biomechanical factors to help in building the recommended model. The most important results showed that the strength of back muscles and the front and back flexibility of legs as well as dynamic balance were the most important physical variables influencing the skill performance where the length of trunk and feet were the most important anthropometric variables influencing this skill performance. The researcher recommends applying further researches to build similar models for other skills depending on the biomechanical profile of the skill.
\end{abstract}

\section{Introduction and research problem:}

The recent huge progress in sports training led to superior performances that aim to reach the highest possible level. Modern technology for measurements in biomechanics is one of the factors that helped in these major steps of sports training that resulted in using modern technological methods in teaching, learning and developing sports skills and movements and promoting the technical performance through measuring variables and processing data to achieve peak performance. $(1: 1) ;(4: 421) ;(7: 8)$.

Studying the kinematics of sports performance is one of the most complicated problems and this can be referred to the difficulty of controlling these variables the influencing factors. (7:8)

Scientific research always tries to solve these problems that are related to movement performance using scientific methods that lead to analyze and develop performance according

\footnotetext{
* Assistant Professor, Sports Training and Kinesiology Department, Faculty of Physical Education for Girls, Alexandria University, Egypt.
}

to the level of athletic abilities. This is why it is very necessary to use biomechanical applications to help in achieving the best possible performance where we can identify the timing structure for each part of the skill where the athlete is obliged to exert his best speed and strength as a basic mechanical target and as a condition of performance as well which in turn enables directing the training process according to the dynamic components of each and every skill. (6:251)

Antonio Cicchella (2009) mentioned that the basic process of understanding that is based on the descriptive analysis of biomechanical sports performance variables is the main base of building sports training. (19:41)

Evaluation is considered to be the best method for developing and promoting sports performance as it helps in discovering the points of weakness and strength and the rates of performance development and avoiding errors in addition to confirming the efficiency of the applied training methods and its suitability (1:2). This process is based on three dimensions psychological, physiological and mechanical. 
Adel Abd Elbaseer (2004) and Ihab Adel et al (2005) confirmed that sports performance biomechanical analysis is the main tol through which technical and skill performance can be studied efficiently to identify the forming factors through using modern technological devices in recording and analyzing performance in and integral way with human and physical sciences. This enables coaches and trainers in determining the sensitive points in athletes' skill performance and the deep understanding of performance development and promotion process. (2:2), (3:2-6)

The mechanical aspect is one of the most important aspects of evaluating skill performance depending on a clear curriculum of descriptive biomechanical analysis through measuring distances and times as well as the affecting forces in a digital way which enhances its reliability in the process of evaluation. (8:3)

The deep study of performance mechanical properties leads to a subjective judgment on the level of mastering sports skills which gives an opportunity to a positive interference that aims for developing the sports technique. (16),(17)

Popovic et al (2006) confirmed that developing sports technique is the main mission of sports training and its efficiency depends on the mechanical variables and individual differences among athletes. (20:1)

On the other hand technical and mechanical aspect must be highly considered and studied as an integrated and joined factor that helps in identifying the determents of model technique which is used in evaluating the levels of skill performance as only studying the outputs of biomechanical analysis will only be useful in having a numerical values for the player's performance and these values will not have any meaningful significance unless they will be studied as one integrated component in the light of the technical specifications of the international rhythmic gymnastics federation in relation with the chosen skill performance. (11:79)

In spite of the growing popularity of rhythmic gymnastics, and the peak technical performance of the female players due to the development of training methods and using modern technology in training process, yet biomechanical analysis has not been fully discovered as a new field and this can be easily concluded through the few number of studies and researches that has been conducted in the field of biomechanical analysis in rhythmic gymnastics generally and in flexibility skills specifically. This causes many difficulties for coaches and trainers when they intend to analyze performance errors. (19:41),(21:416), (15:11), (13:20)

The importance of flexibility exercises in rhythmic gymnastics can be referred to its being the main factor in all movement and skill groups (jumps - balances - turns ...) where the female player tries to show the high flexibility of her body movements. The difficulty of performing these skills lies in its demands of high coordination and high range of motion in all body joints as well as higher strength and control ((13)). In addition to that the movements should be characterized with consistency and determination as well as the continuity of the series of skills without any pauses. (9:37).

Although back-telna-back skill is one of the highest difficulty rates $(G)$ in rhythmic gymnastics as it values 0.7 (Law:43), but it is also one of the most common and well-spread skills in national and international competitions. And this was obvious in the analysis of the high level players in addition to confirming this concept through personal interviews with coaches and judges which was the biggest motive for conducting further research on this skill.

It is clear from what is mentioned above that analyzing performance biomechanically is of high importance to evaluate technical performance but ti is not yet well discovered as only 2 researches have been conducted in basketball (omaima elagamy, 2004) and volleyball (mahasen elwan,2008), where no researches or studies were conducted in rhythmic gymnastics and flexibility skills according to the researcher's survey on the world wide web, this is why the researcher conducted this study to build an evaluation model for back-tlna-back skill in the light of the biomechanical profile through determining the most important biomechanical variables that affect performance and designing an evaluation card as a subjective assessment tool which allows identifying the level of the player's 
performance through deeper understanding of skills and helping to develop and promote and direct the training process.

\section{Research aim:}

Building an evaluation model for back-telnaback skill in the light of the biomechanical profile through:

1. Determining the physical and anthropometric measurements that are related to this skill.

2. Determining the biomechanical variables that are related to this skill in the light of biomechanical analysis.

3. Identifying the mechanical profile of this skill in the light of anthropometric and physical measurements as well as biomechanical variables.

4. Designing an evaluation card of this skill in the light of anthropometric and physical measurements as well as biomechanical variables.

\section{Research procedures:}

\section{Research method}

The descriptive analytical method has been used due to its suitability with the research nature.

\section{Research sample:}

It was picked intentionally among distinguished rhythmic gymnastics players $(\mathrm{N}=6)$ according to:

1. The level of performing back-telna-back skill

2. Players should be registered in the Egyptian gymnastics federation

3. Players represented Egypt in many international competitions and events.

Tables 1, 2 and 3 represents the anthropometric and physical measurements of the research sample

Table (1)

The statistics of the primary variables for the research sample $N=6$

\begin{tabular}{|c|c|c|c|}
\hline \multirow{2}{*}{ Variables } & \multicolumn{3}{|c|}{ Statistical significance } \\
\cline { 2 - 4 } & Mean & Median & $\begin{array}{c}\text { Std. } \\
\text { Deviation }\end{array}$ \\
\hline Age & 17.005 & 17.453 & 1.221 \\
\hline Length & 165.995 & 165.582 & 2.689 \\
\hline Weight & 42.245 & 42.658 & 2.153 \\
\hline
\end{tabular}

(**) Correlation is significant at the 0.01 level $=0.874$

(*) Correlation is significant at the 0.05 level $=0.754$

Table (2)

The statistics of some of the anthropometric variables $N=6$

\begin{tabular}{|c|c|c|c|c|c|}
\hline \multirow{2}{*}{ Variables } & \multicolumn{3}{c|}{ Statistical significance } & \multirow{2}{*}{ correlation } \\
\cline { 3 - 6 } & \multirow{2}{*}{} & Mean & Median & $\begin{array}{c}\text { Std. } \\
\text { Deviation }\end{array}$ & \\
\hline \multirow{4}{*}{ Lengths } & Humerus & 30.530 & 30 & 0.351 & $* 0.774$ \\
\cline { 2 - 6 } & Forearm & 24.195 & 24.5 & 1.013 & 0.159 \\
\cline { 2 - 6 } & Hand & 19.050 & 19 & 0.920 & 0.367 \\
\cline { 2 - 6 } & Trunk & 46.060 & 46 & 1.643 & $* 0.821$ \\
\cline { 2 - 6 } & Thigh & 36.450 & 36 & 0.887 & $* 0.783$ \\
\cline { 2 - 6 } & Leg & 42.900 & 42 & 0.822 & $* 0.768$ \\
\cline { 2 - 6 } & Foot & 24.610 & 24 & 1.128 & $* 0.843$ \\
\hline
\end{tabular}

(**) Correlation is significant at the 0.01 level $=0.874$

(*) Correlation is significant at the 0.05 level $=0.754$ 
Table (3)

The statistics of some of the physical variables $N=6$

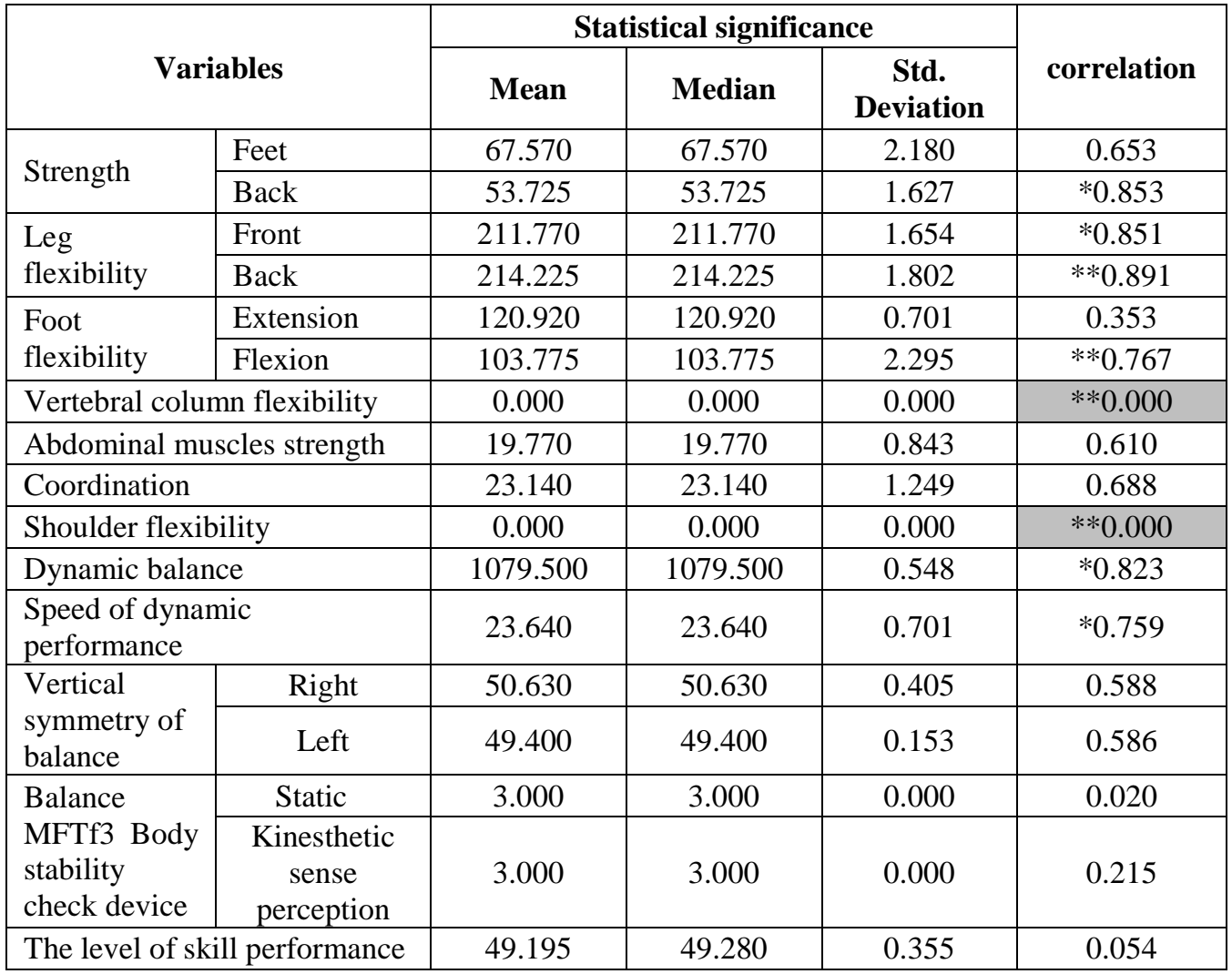

(**) Correlation is significant at the 0.01 level $=0.874$

(*) Correlation is significant at the 0.05 level $=0.754$

\section{Time scope:}

Research was conducted during the period from 11 to $131 / 2011$.

\section{Place scope:}

Recording performance and measurements were done in the sporting hall in the Faculty of Sports for Girls - Alexandria University.

\section{Data collection tools:}

\section{Research measurements:}

1. Anthropometric measurements "As mentioned in table $2 "$

2. Physical measurements "As mentioned in table 3"

3. Evaluating the back-telna-back skill through 3 international judges using the skill evaluating sheet (annex 1) through taking the mean of the 3 marks.

\section{Video recording and kinematographic analysis:}

1. A Panasonic video camera Model M3000 was used to record performances on raw video tapes.

The camera was placed on a tripod on the same height level of performing back-telna-back skill, as 2 . The camera was in front of the player at a distance of $5.7 \mathrm{~m}$ with a height of $1.4 \mathrm{~m}$ off the floor with a lens opening no. 1 and a frequency of 25 frames per second. The player's joints were marked for analysis purposes.

3. 3 trials were recorded for back-telna-back skill for each player where the best trial was chosen. Then the skill was divided into 4 stages, prepatory stage, then back split with help, then front split with trunk bent back-telna and ending by back split with help and final stage.

4. Where the biomechanical variables of each stage were determined for center of gravity for the body and for the moving arm and both of the moving leg and the stable leg in addition to the kinematical angular variables for the body joints." Annex ??" 


\begin{tabular}{|c|c|c|}
\hline Mechanical variables & Mechanical symbols & Measurement units \\
\hline Horizontal velocity & v_x & {$[\mathrm{m} / \mathrm{s}]$} \\
\hline Vertical velocity & v_y & {$[\mathrm{m} / \mathrm{s}]$} \\
\hline Quantum velocity & v_mag & {$[\mathrm{m} / \mathrm{s}]$} \\
\hline Horizontal acceleration & x-accel. & {$\left[\mathrm{m} / \mathrm{s}^{\wedge} 2\right]$} \\
\hline Vertical acceleration & a_y & {$\left[\mathrm{m} / \mathrm{s}^{\wedge} 2\right]$} \\
\hline Quantum acceleration & a_mag & {$\left[\mathrm{m} / \mathrm{s}^{\wedge} 2\right]$} \\
\hline Amount of horizontal movement & mmntm_x & {$[\mathrm{kg} \mathrm{m} / \mathrm{s}]$} \\
\hline Amount of vertical movement & mmntm_y $/ \mathrm{s}]$ \\
\hline Quantum movement & mmntm_mag & {$[\mathrm{kg} \mathrm{m} / \mathrm{s}]$} \\
\hline Horizontal force & F_x & {$[\mathrm{N}]$} \\
\hline Vertical force & F_y & {$[\mathrm{N}]$} \\
\hline Quantum force & F_mag & {$[\mathrm{deg}]$} \\
\hline Elbow angle of moving arm & $\Theta$ & {$[\mathrm{deg}]$} \\
\hline Shoulder angle of moving arm & $\Theta$ & {$[\mathrm{deg}]$} \\
\hline Hip angle of leg of moving arm & $\Theta$ & {$[\mathrm{deg}]$} \\
\hline $\begin{array}{c}\text { Hip angle of contralateral leg of } \\
\text { moving arm }\end{array}$ & $\Theta$ & {$[\mathrm{deg}]$} \\
\hline Pelvic angle & $\Theta$ & {$[\mathrm{deg}]$} \\
\hline Knee angle of leg of moving arm & $\Theta$ & {$[\mathrm{deg}]$} \\
\hline $\begin{array}{c}\text { Knee angle of contralateral leg of } \\
\text { moving arm }\end{array}$ & $\Theta$ & {$[\mathrm{deg}]$} \\
\hline Foot angle of leg of moving arm & $\Theta$ & {$[\mathrm{deg}]$} \\
\hline $\begin{array}{c}\text { Foot angle of contralateral leg of } \\
\text { moving arm }\end{array}$ & $\Theta$ & \\
\hline
\end{tabular}

5. The recorded trials were transferred to the computer and saved with an AVI extension that was changed to MPG. The trials were cut into smaller movies using VCD cutter, where these smaller parts were cut into 25 frames per second using VP Capture software. Afterwards Video point V 2.5 was used for analyzing the required frames before starting the trial with 2 frames until the last frame where the player stops.

In order to build this evaluation model for backtelna-back, the following steps should be followed:

1. Analyzing the skill according to the determined stages to extract the biomechanical variables.

2. Finding the correlation coefficient between these biomechanical variables, the anthropometric measurements and the physical variables and between the levels of performing back-telna-back skill.
3. Forming a graphical data net for the most effective biomechanical variables for backtelna-back skill according to the higher correlation coefficient for these variables.

4. Using the assessment card as a mean for building the triple measurement tool according to the nature of the research sample and the nature of the biomechanical variables.

\section{Statistical processing:}

The researcher used the following statistical processing tools due to their suitability for the research nature:

- Arithmetic mean

- Median

- Standard deviation

- Correlation coefficient 


\section{Results and discussions:}

1st: Results and discussion for the anthropometric and physical measurements and its relation with the level of skill performance:

Table (4)

The most correlative anthropometric measurements with the level of skill performance $N=6$

\begin{tabular}{|c|c|c|c|c|c|}
\hline \multicolumn{2}{|c|}{ Variables } & \multicolumn{3}{c|}{ Statistical significance } & \multirow{2}{*}{ correlation } \\
\cline { 3 - 5 } & Mean & Median & Std. Deviation & \\
\hline \multirow{2}{*}{ Lengths } & Trunk & 46.06 & 46 & 1.643 & $* 0.821$ \\
\cline { 2 - 5 } & Feet & 24.61 & 24 & 1.128 & $* 0.843$ \\
\hline
\end{tabular}

(**) Correlation is significant at the 0.01 level $=0.874$

(*) Correlation is significant at the 0.05 level $=0.754$

Figure (1)

The anthropometric characteristics profile with highest significance with the level of skill performance.

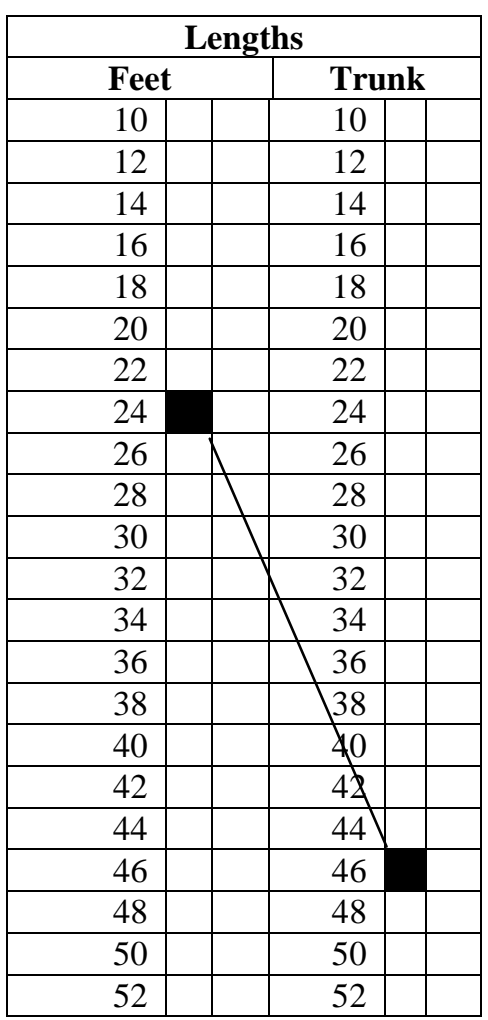

Table (4) and Figure (1) shows that the most relevant anthropometric measurements to the level of skill performance were the length of trunk and feet with a correlation coefficient of 0.82 and 0.84 respectively. 
Table (5)

The most correlative physical variables with the level of skill performance $N=6$

\begin{tabular}{|c|c|c|c|c|}
\hline \multirow[b]{2}{*}{ Variables } & \multicolumn{3}{|c|}{ Statistical significance } & \multirow[b]{2}{*}{ Correlation } \\
\hline & Mean & Median & $\begin{array}{c}\text { Std. } \\
\text { Deviation }\end{array}$ & \\
\hline $\begin{array}{l}\text { Back muscles } \\
\text { strength }\end{array}$ & 53.725 & 53.725 & 1.627 & $* 0.853$ \\
\hline $\begin{array}{l}\text { Front leg } \\
\text { flexibility }\end{array}$ & 211.77 & 211.77 & 1.654 & $* 0.851$ \\
\hline $\begin{array}{l}\text { Back leg } \\
\text { flexibility }\end{array}$ & 214.225 & 214.225 & 1.802 & $* * 0.891$ \\
\hline Dynamic balance & 1079.5 & 1079.5 & 0.548 & $* 0.823$ \\
\hline
\end{tabular}

Figure (2)

The physical variables profile with highest significance with the level of skill performance.

\begin{tabular}{|c|c|c|c|c|}
\hline \multicolumn{5}{|c|}{ Physical variables } \\
\hline $\begin{array}{l}\text { Dynamic } \\
\text { balance }\end{array}$ & $\begin{array}{c}\text { Back leg } \\
\text { flexibility }\end{array}$ & $\begin{array}{l}\text { Front leg } \\
\text { flexibility }\end{array}$ & \multicolumn{2}{|c|}{$\begin{array}{c}\text { Back } \\
\text { muscles } \\
\text { strength }\end{array}$} \\
\hline 1005 & 110 & 110 & 10 & \\
\hline 1010 & 120 & 120 & 15 & \\
\hline 1015 & 130 & 130 & 20 & \\
\hline 1020 & 140 & 140 & 25 & \\
\hline 1025 & 150 & 150 & 30 & \\
\hline 1030 & 160 & 160 & 35 & \\
\hline 1035 & 170 & 170 & 40 & \\
\hline 1040 & 180 & 180 & 45 & \\
\hline 1045 & 190 & 190 & 50 & \\
\hline 1050 & 200 & 200 & 55 & \\
\hline 1055 & 210 & 210 & 60 & \\
\hline 1060 & 220 & 220 & 65 & \\
\hline 1065 & 230 & 230 & 70 & \\
\hline 1070 & 240 & 240 & 75 & \\
\hline 1075 & 250 & 250 & 80 & \\
\hline 1080 & 260 & 260 & 85 & \\
\hline 1085 & 270 & 270 & 90 & \\
\hline 1090 & 280 & 280 & 95 & \\
\hline 1095 & 290 & 290 & 100 & \\
\hline 1100 & 300 & 300 & 105 & \\
\hline
\end{tabular}

Table (5) and Figure (2) shows that the most relevant physical variables to the level of skill performance were the strength of back muscles and the front and back flexibility of legs as well as dynamic balance with a correlation coefficient of $0.85,0.85,0.89,0.82$ respectively. Where these measurements were the determents of building the mechanical profile of this skill where the researcher depended on the value of correlation between the performance level and the research variables when it is only more than 0.7 .
Tables (2) and (3) show that the anthropometric and physical variables with the highest correlation coefficient were:

1. The length of the trunk with an arithmetic mean of 46.06 and a correlation coefficient of 0.821

2. The length of the feet with an arithmetic mean of 24.61 and a correlation coefficient of 0.843 
3. The strength of the back muscles with an arithmetic mean of 53.725 and a correlation coefficient of 0.853

4. The front flexibility of the right leg with an arithmetic mean of 211.77 and a correlation coefficient of 0.851

5. The back flexibility of the left leg with an arithmetic mean of 214.225 and a correlation coefficient of 0.891

6. The dynamic balance with an arithmetic mean of 1079.5 and a correlation coefficient of 0.823

7. The flexibility of the vertebral column and shoulder joint, where the results of these measurements shows that the research sample is characterized with extreme flexibility rates where they scored the best level with zero degree,

These results agree with the requirements of technical performance of back-telna-back skill where the relation between these variables proves the high effect of dynamic and static balance on the ability of correct performance of back-telna-back skill and as for static balance, the length of feet is one of the most important determents of the ability of static balance.

This agrees with what Pica (2000) mentioned when he confirmed the importance of the length of feet in balance tasks as it represents the base of the whole body in static tasks(14:45). Where this also interferes with the degree of flexibility of thighs as the angle of range of motion for both joints should reach 180 o back and front to achieve the perpendicularity of the free leg on the base foot which means the presence of the arm of force on the same straight line with the static base and with the line of centre of gravity which guarantees the successful balance when performing similar skills.

The strength of back muscles also is a strong factor to aid in the process of static balance and consistency; also it helps in the highest rate of extension in the second stage of the skill which allows reaching the peak trunk back bent. This was also confirmed by Costilletal et al (1992) who proved that developing the flexibility of the vertebral column achieves better static balance timing which in turn serves the performance of the skill. (10)

On the other hand, performing back-telna-back skill depends on dynamic balance in the intrastages when the pivoting is transferred from one leg to another and it has been also proved through the correlation between the length of trunk and the dynamic balance which needs achieving the balanced relation between force "moving leg" and resistance "trunk length".

This way, the first aim of this study is accomplished through determining the most relevant anthropometric and physical variables with the level of performing back-telna- back skill in rhythmic gymnastics.

2nd: Results and discussion for the biomechanical variables of the 3 stages of the skill and its relation with the level of skill performance: 
Table (6)

The most relevant biomechanical variables with the level of skill performance.

\begin{tabular}{|c|c|c|c|c|c|c|}
\hline \multirow{2}{*}{$\begin{array}{l}\text { Performance } \\
\text { moment }\end{array}$} & \multirow[b]{2}{*}{ Variables } & \multicolumn{4}{|c|}{ Statistical significance } & \multirow[b]{2}{*}{ correlation } \\
\hline & & Mean & Median & $\begin{array}{c}\text { Std. } \\
\text { Deviation }\end{array}$ & Skewness & \\
\hline \multirow{2}{*}{$\begin{array}{c}\text { When the left leg with } \\
\text { a } 45^{\circ} \text { back angle to } \\
\text { the ground in the first } \\
\text { skill }\end{array}$} & $\begin{array}{l}\text { The vertical force of } \\
\text { the left arm center of } \\
\text { gravity }\end{array}$ & 18.523 & 16.27 & 2.804 & 1.646 & $* 0.852$ \\
\hline & $\begin{array}{c}\text { The vertical velocity } \\
\text { of the left leg center } \\
\text { of gravity }\end{array}$ & 1.768 & 1.762 & 0.045 & 0.56 & $* 0.840$ \\
\hline \multirow{2}{*}{$\begin{array}{l}\text { The back maximum } \\
\text { extension of the left } \\
\text { leg in the first skill }\end{array}$} & $\begin{array}{c}\text { The knee angle of the } \\
\text { left leg }\end{array}$ & 162 & 162.3 & 2.663 & -0.501 & $* 0.852$ \\
\hline & Pelvic angle & 188.54 & 187.5 & 2.265 & 0.879 & $* 0.865$ \\
\hline $\begin{array}{l}\text { When the right leg is } \\
\text { forming a front angle } \\
\text { of } 45^{\circ} \text { with the ground } \\
\text { in the second skill }\end{array}$ & $\begin{array}{l}\text { Total force of centre } \\
\text { of gravity for right leg }\end{array}$ & 69.563 & 67.21 & 5.501 & 1.573 & $* 0.822$ \\
\hline \multirow{2}{*}{$\begin{array}{l}\text { Maximum front } \\
\text { extension for the right } \\
\text { foot }\end{array}$} & $\begin{array}{l}\text { The left thigh joint } \\
\text { angle }\end{array}$ & 74.467 & 72.8 & 7.128 & 1.732 & $* 0.815$ \\
\hline & Pelvic angle & 182.546 & 180.58 & 1.547 & 0.792 & $* 0.857$ \\
\hline \multirow{2}{*}{$\begin{array}{l}\text { When the right leg is } \\
\text { forming a back angle } \\
\text { of } 45^{\circ} \text { with the ground } \\
\text { in the third skill }\end{array}$} & $\begin{array}{c}\text { Quantum movement } \\
\text { of center of gravity of } \\
\text { left leg }\end{array}$ & 11.102 & 11.43 & 1.147 & -1.18 & $* 0.805$ \\
\hline & $\begin{array}{c}\text { Right shoulder joint } \\
\text { angle }\end{array}$ & 168.59 & 170.7 & 4.721 & -1.727 & $* 0.832$ \\
\hline \multirow{2}{*}{$\begin{array}{c}\text { Maximum back } \\
\text { extension for the left } \\
\text { leg }\end{array}$} & Left knee joint angle & 181.167 & 180.7 & 1.361 & 1.361 & $* 0.868$ \\
\hline & Pelvic angle & 185.652 & 185.456 & 1.582 & 0.947 & $* 0.838$ \\
\hline
\end{tabular}

Table (6) shows that the centre of gravity of the right arm and the vertical velocity of the left leg with a 45o back angle to the ground in the first skill with a median of 18.523 and 1.768 respectively.

The knee angle of the left leg as well as the pelvic angle in the moment of maximum back extension of the left leg in the first part of skill with medians of 162 and 188.54 respectively.

The sum of forces of centre of gravity for right leg when the right leg is forming a front angle of $45 \mathrm{o}$ with the ground in the second skill with median 69.563 .

The left thigh joint angle as well as the pelvic angle during the maximum front extension for the right foot in the second part of the skill with medians 74.467 and 182.546 respectively.

Quantum movement of center of gravity of left leg during and the right shoulder joint angle when the right leg is forming a back angle of
450 with the ground in the third skill with medians 11.102 and 168.59 respectively.

The left knee joint angle and the pelvic angle during the maximum back extension for the left leg in the third skill with medians 181.167 and 185.652 respectively.

The researcher's analysis to the mathematical relations that affects the biomechanical variables of the sports performance as in the first and third skill where the relation between the vertical force of the right arm and the angle of the right shoulder joint which confirms the role of the muscular strength which led to holding the left leg in the suitable moment and in the nearest point to the perpendicular line of action of force. Jan Babič \& Jadran Lenarčič(2007) clarified that job of the muscles is to produce vertical impulse of the center of gravity of the body and to transfer from position of half bent of the supporting leg into the position of complete extension of the knee of supporting leg in the vertical direction to the 
position of high back balance ( in the first skill) and during impulse of the free leg extended freely vertically and to the back, the body center of gravity should be above the base of support formed by the foot.Omima Alagamy

$$
\stackrel{A}{F}=\int_{t_{1}}^{t_{2}} F d t=\int_{V_{1}}^{V_{2}} m d t=\left(m V_{2}-m V_{1}\right)=m\left(V_{2}-V_{1}\right)
$$

Where $\mathrm{F}$ is impulse, $\mathrm{F}$ is mean force, $\mathrm{dt}$ is time of effect of force and (mV1-mV2) is the change in quantum movement. The last relation clarifies integration between function of force and time in two moments by knowing the effective force, this is called push force and it equals the change in quantum movement and hence it is clear that change in speed of the player does not depend only on the force but also on the time of force ( 1:26) As well as the positive relationship between the vertical velocity of the center of gravity of the left leg where the quantum movement equals mass multiply velocity

Quantum movement $=$ Mass $\mathrm{x}$ Velocity $=\mathrm{M} \mathrm{x}$ (V1 - V2 ) (12:137)

which confirms the importance of applying the appropriate speed on the left leg to meet the right arm in the suitable moment of time which preserves the body balance during performing the first and third skill with a back angle of 450 to the ground.

Also the results show the identical model of the knee and pelvic angles in the moment of maximum back extension of the left leg in the first and third skills which confirms the
(2004) mentioned queted from Burnett(2004) that impulse is push of a force to a body during period of time and equals the change happening in the quantum movement during this period(1:26) according to the equation: necessity of reaching the perpendicular position to be identical with the vertical axis of the center of gravity which leads to preserving the best body balance. This relation also confirms the importance of flexibility of legs and thighs to achieve the best possible pelvic angle $180 \mathrm{o}$ which helps in reaching the left leg to the vertical perpendicular position on the ground.

In the second skill the sum of forces of the right leg in the moment of moving the leg with a 450 angle to the ground which helped the player to reach the maximum possible pelvic angle of $180 \mathrm{o}$ which leads to preserving the best possible balance as well.

All these findings confirm the effect and relationship between these biomechanical variables and the level of performing backtelna-back skill in rhythmic gymnastics. These variables also are considered to be a very good indicator for achieving the best performance level as per the below figure which explains the detailed model of technical performance of this skill for the 3 stages of performance as well as the time required for each stage. 


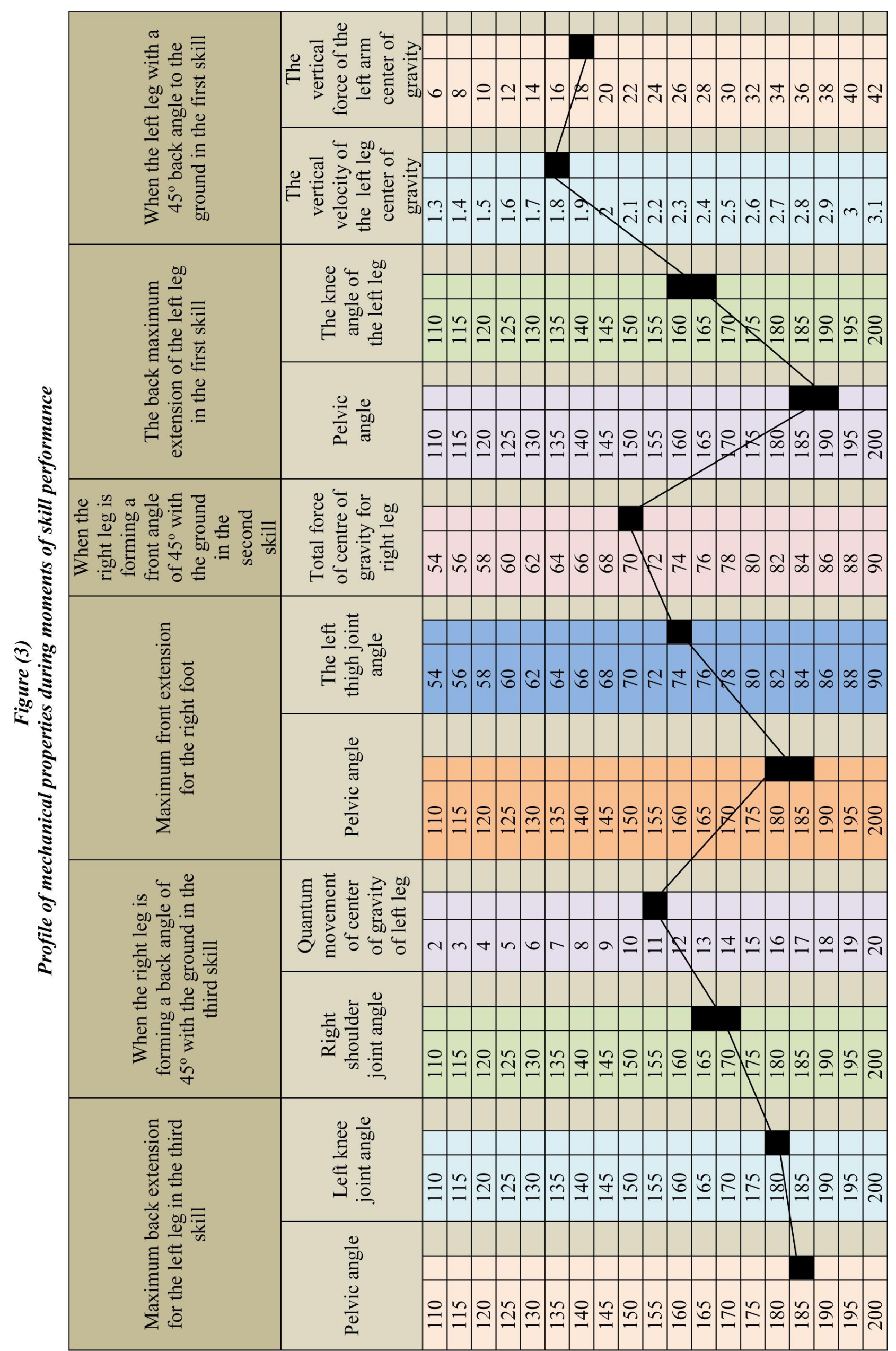


Figure (4)

A model for the chronology of the performance of back telna back skill of the player Jasmine Rostam, which Displays the number of staff and time the bottom of each moment in the three phases of the performance of the skill in question

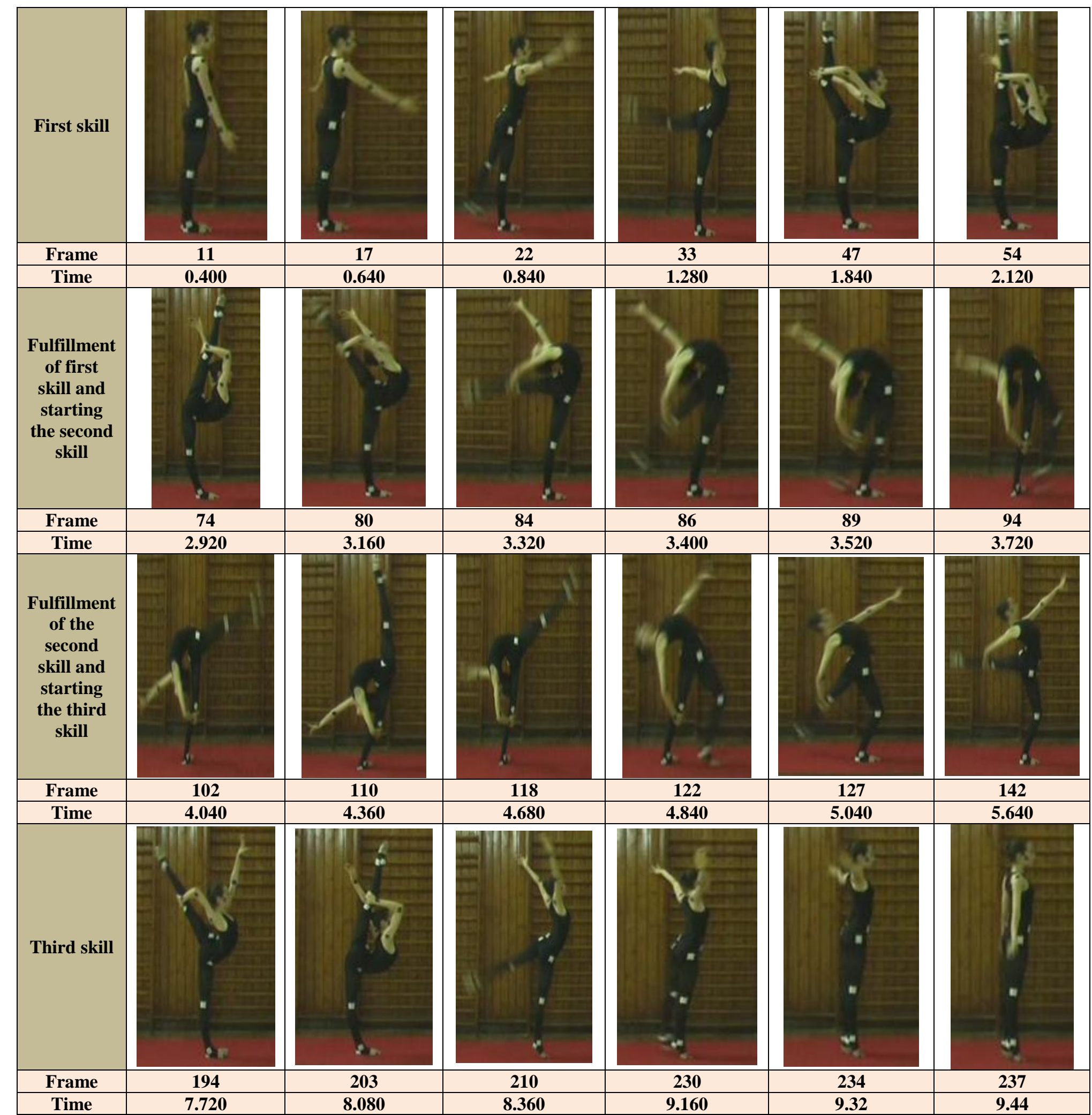




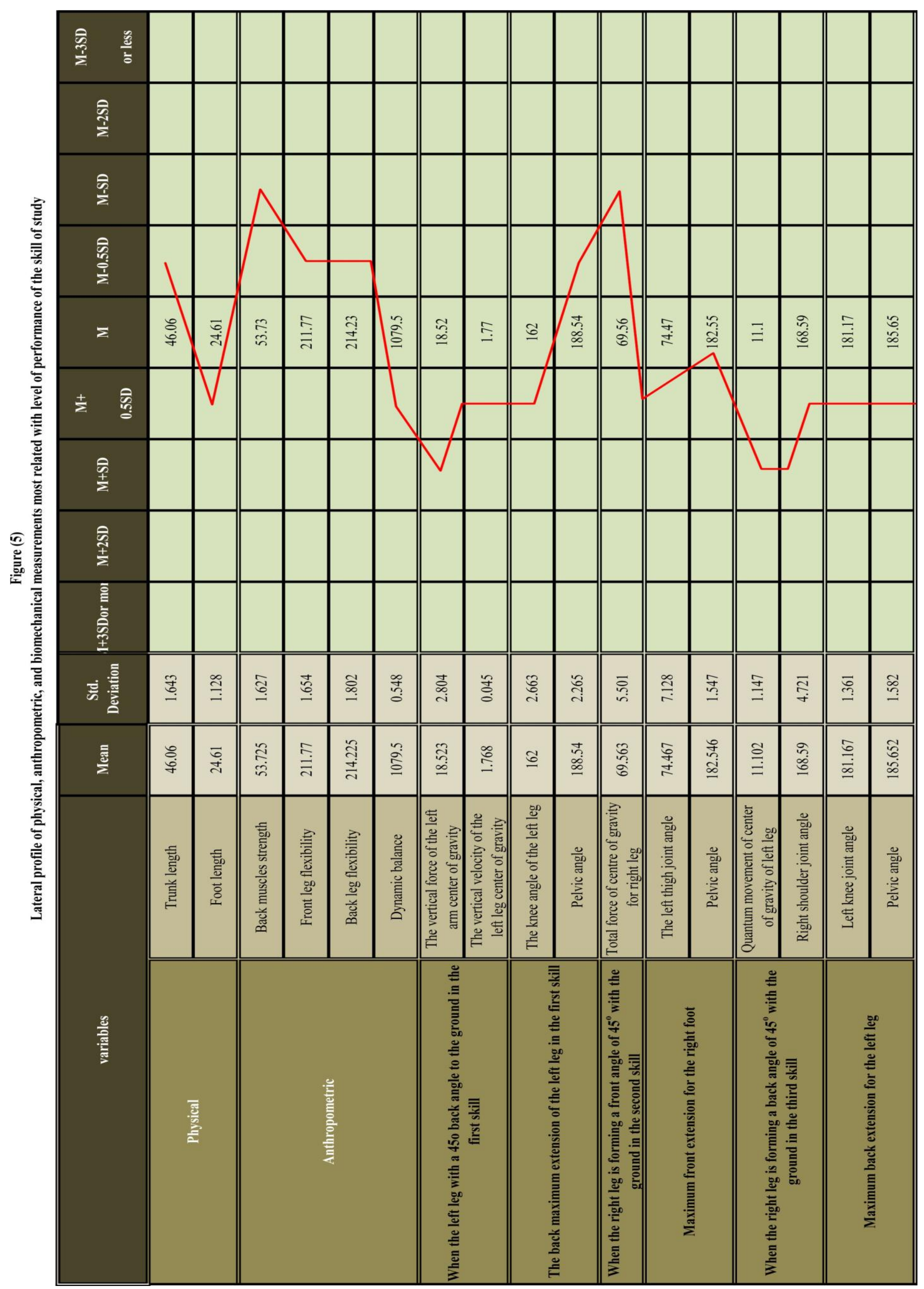


According to the former an evaluation card was designed for the skill of the research, and that led to access to the fourth aim of this research. This card aimed at evaluation of the level of the player and its order among specific group and it depends on the median degree as a triple measurement tool , in addition to recording some principle informations of the player. The card was made in the following steps:

1. Determination of the most effective dynamic characteristics in perfoming back telna back in Rhythmic Gymnastics.

2. Determination of the median as in table (6).

3. Making a separate card for each player to record her dynamic characteristics, and the triple measurement is built according to the median, and it is considered the point of discrimination between the week and accepted levels where the median is rated as 2 degrees, while below it is 1 degree and above it is 3 degrees.This depends on the nature of the variable, so if decreasing the value of the variable goes well with the level of performance, we consider the higher degree. For example reduction of the duration of damping phase leads to more impulse, whereas increase of flight phase duration leads to better performance. So value of the charecteristics depends on the nature of each variable and its effect on the performance (Figure 6)
4. Putting points against each variable for the player, and by connecting them we obtain a graphic determining level and order of the player, and it is possible to modify the median upwards or downwards according to the nature of the evaluated sample. The characteristic curves of the skill and diagram network are coupled with the card so it is possible to obtain a simple model for performance evaluation.

5. Judging of the performance of the player and its order among her group.

6. Detection of the defect of any mechanical variable which leads to modification of training increasing its effectiveness.

7. Use of this model in evaluation of the player pre and post training or in comparison between the player and other players, as making a profile each time and for each player on the network by a particular colour or configuration for each profile which serves in evaluation of the degree of progress.

8. The card can involve more than one field of evaluation fields as the physical one, and also information of the player and her behavior.

9. Issue a rule and decision depending on weakness aspects according to the card in order to investigate the causes of this weakness and the way of solution. 
Figure (6)

Evaluation card for back telna back skill in Rhythmic Gymnastics

There are 11 dynamic variables and as the maximum degree of each variable is 3 degrees so sum of degrees is 33 degrees so degrees of each player is summed

\section{Evaluation card for back telna back skill in Rhythmic Gymnastics}

\begin{tabular}{|c|c|c|c|c|c|c|c|}
\hline level & Median & More & Median & Less & $\begin{array}{c}\text { Mechanical } \\
\text { symbol }\end{array}$ & \multicolumn{2}{|c|}{ Variables } \\
\hline 3 & 18.523 & & & & Fy & $\begin{array}{l}\text { The vertical force of the } \\
\text { left arm center of gravity }\end{array}$ & \multirow{2}{*}{$\begin{array}{l}\text { When the left leg } \\
\text { with a } 45^{\circ} \text { back } \\
\text { angle to the ground } \\
\text { in the first skill }\end{array}$} \\
\hline 3 & 1.768 & & & & Vy & $\begin{array}{c}\text { The vertical velocity of } \\
\text { the left leg center of } \\
\text { gravity }\end{array}$ & \\
\hline 3 & 162 & & & & $\theta$ & $\begin{array}{l}\text { The knee angle of the left } \\
\text { leg }\end{array}$ & \multirow{2}{*}{$\begin{array}{l}\text { The back maximum } \\
\text { extension of the left } \\
\text { leg in the first skill }\end{array}$} \\
\hline 1 & 188.54 & & & & $\theta$ & Pelvic angle & \\
\hline 3 & 69.563 & & & & F_mag & $\begin{array}{l}\text { Total force of centre of } \\
\text { gravity for right leg }\end{array}$ & $\begin{array}{l}\text { When the right leg is } \\
\text { forming a front angle } \\
\text { of } 45^{\circ} \text { with the } \\
\text { ground in the second } \\
\text { skill }\end{array}$ \\
\hline 2 & 74.467 & & & & $\theta$ & The left thigh oint angle & \multirow{2}{*}{$\begin{array}{l}\text { M ximum front } \\
\text { extension for the } \\
\text { right foot }\end{array}$} \\
\hline 2 & 182.546 & & & & $\theta$ & Pelvic angle & \\
\hline 3 & 11.102 & & & & mmntm_mag & $\begin{array}{c}\text { Quantum movement of } \\
\text { center of gravity of left } \\
\text { leg } \\
\end{array}$ & \multirow{2}{*}{$\begin{array}{l}\text { When the right leg is } \\
\text { forming a back angle } \\
\text { of } 45^{\circ} \text { with the } \\
\text { ground in the third } \\
\text { skill }\end{array}$} \\
\hline 1 & 168. 9 & & & & $\theta$ & Right shoulder joint angle & \\
\hline 2 & 181.167 & & & & $\theta$ & Left knee joint angle & \multirow{2}{*}{$\begin{array}{c}\text { Maximum back } \\
\text { extension for the left } \\
\text { leg }\end{array}$} \\
\hline 3 & 185.652 & & & & $\theta$ & Pelvic angle & \\
\hline$\frac{26}{33}$ & & 3 & 2 & 1 & & Total scores & \\
\hline
\end{tabular}

Level:29-33(excellent), 25-29(very good), 2125(good), 16-21(average), <16(weak)

Figure (6) shows a sample of evaluation of one player using the card and she gained 26 degrees and her level was $78.78 \%$ ( very good), consequently we can give degree for each step to know aspects of weakness and strength. As an example the player gained $6 / 6$ in movement of the moving leg backwards by angle of 45 degree with the ground while she gained $4 / 6$ during maximum extension of the leg backwards in the first skill. By revision of the variables we found the defect in the pelvis angle . Also she gained 4/6 in backward movement of the leg with 45 angle with ground where the cause of defect was moving arm shoulder angle . In addition she gained 5/6 during maximum backward extension of the leg in the third skill and defect was in the moving leg knee angle.

By analysis of the results the trainer can know weakness and strength aspects in each step of artistic performance and there causes, hence he can treat the defects and improve the performance. 


\section{Conclusions:}

- Determining the most relevant anthropometric and physical variables to the performance of back-telna-back skill.

- Determining the biomechanical variables that are related to this skill in the light of biomechanical analysis.

- Identifying the mechanical profile of this skill in the light of anthropometric and physical measurements as well as biomechanical variables for back-telna-back skill.

\section{Recommendations:}

1. You can count on the diagrams of the mechanical properties of the players delimiters for selection as the source of this is to analyze the determinants of vocabulary and performance requirements in the specific physical activity and become acquainted with the specifications of heroes as their superiority in specific physical activity means that they have the specifications and requirements of this superiority.

2. Application of the proposed card in the manner prescribed and urged the coaches to use and understand the interpretation of the results for ease of use to the importance of the above.

3. Conducting additional research to determine the anthropometric measurements and physical and biomechanical variables most associated with the performance of other skills in rhythmic gymnastics and other sports as well.

4. Modelling of the skills profile for other skills for purpose of education, training, and correcting errors of performance.

\section{References:}

\section{Arabic References:}

1. Omima Ibrahim Alajamy Saleh: Contemporary developments in the technology of biomechanics, scientific articles within the requirements for promotion to the post of Professor in Biomechanics, Sports Training Committee of the functions of teachers; the Standing Scientific Committee of Physical
Education, the Supreme Council of Universities, 2004.

2. Adel Abdelbaseer Ali:Biomechanical analysis of movements founded by the human body and its applications the Arab library for printing, publishing and distribution in Alexandria, 2004.

3. Adel Abdelbaseer \&Ihab Adel: Biomechanical analysis and integration between theory and practice in the field of sports, United Printing and Imaging, Port Said, 2005.

4. Karem Metwali Mustafa:Electronic model to determine the default path and some of the kinematic variables of movement of extruded body by virtual information of some tee variables, International Scientific Conference XIII - Physical Education and Sports (the challenges of the third millennium) - Faculty of Physical Education for Men pyramid - Helwan University - 23 to 24 March - the folder 2010

5. Mahasen Elwan\& Nadia Rashwan: Build a calendar in the light of the biomechanical variables for rollback skill in volleyball, search within the requirements for promotion to the post of Professor of Biomechanics, Fourth Regional Conference of the International Council for Health and Physical Education, Recreation and Sport and kinetic expression of the Middle East, College of Physical Education for Men, Alexandria University, 2008

6. Mohamed Ahmed Ramzi\&Gamal Imam Alsayed: Use of weight training in the development of effective mechanical and the digital level for beginners of the long jump, Journal of Physical Education and Sports Number of (46) - Faculty of Physical Education for Men. Pyramid Region - Helwan University - January 2006

7. Mohamed Sabri Omar: Trends of scientific research in the physical and biological determinants of the selection in the light of technological development and the information revolution, article publication, International Scientific Conference, Faculty of Physical Education for Men in Alexandria, 2002.

\section{Foreign References:}

8. Barhom, M.J (1988): Mechanical Kinesiology, Saint Louis. The C.V. Mosby Company. 
9. Code of Points (2009): International Gymnastics Federation: Code of Points, Rhythmic Gymnastics (2009-2012): Version June 2008: Copyright by FIG: Switzerland.

10. Costilletal D. L., Meglischo E. W. \& Richardson A. B. (1992): Swimming Black Well Scientific Publications, London.

11. Dillman,C.j.; Chzethom,P.J. \& Smith,S.L. (1985): Axinematic Analysis of Man's Olympic Long Horse Vaulting, International Journal of Sport Mechanics, May.

12. Grimshaw, Paul; Lees; Adrian; Fowler, Neil \& Burden, Adrian (2007): Sport \& Exercise Biomechanics, BIOS Instant Notes series, Taylor \& Francis, UK.

13. Jasterjembskaia, Nadejda \& Titov , Yuri (1999): Rhythmic Gymnastic: Hoop-Ball-ClubsRibbon Rope; Human Kinetic.

14. Luhtanen, Pekka (2000): For Better Biomechanical Understanding, The Future Research Institute For Sports.

15. Novic, Tigana Pioury; Bobang, Sasa; Popovic, Ruzena; Nkovic, Ratskosta \& Bobang, Radoslav (2010): Comparative Kinematic Analysis of Different Split Front Leaps; Sport Science 3

16. Verduci, F.M. (1980): Measurement Conserts in Physical Education, C.V. Mosby Company, Saint Louis.

17. Welles, K.F.J. (1986): Scientific Basis of Human Motion, Philadelphia W.B.Saunders Co.
18. Babič, Jan \& Lenarčič, Jadran (2007): Jožef Stefan Institute ; Slovenia; Vertical Jump: Biomechanical Analysis and Simulation Study; Humanoid Robots, New Developments, Vienna, Austria; June.

http://www.google.com.eg/search?hl=ar\&q=vert ical+jump+analysis\&btnG $=\% \mathrm{D} 8 \% \mathrm{~A} 8 \% \mathrm{D} 8 \% \mathrm{~A}$ $\mathrm{D} \% \mathrm{D} 8 \% \mathrm{AB} \% 21 \&$ meta

19. Cicchella, Antonio (2009): Kinematic Analysis of Selected Rhythmic Gymnastic leaps, Journal of Human Sport and exercise online (J. Hum. Sport Exerc.): An International Electronic Journal: Vol.4 - No. 1, Official Journal of the Area of Physical Education and Sport, Faculty of Education, University of Alicante, Spain.

http://rua.ua.es/dspace/bitstream/10045/8968/1/ E_JHSE_4_1_5.pdf

20. Ruzena, Popovic \& Dragana, Aleksic (2006): The Relations of the Morphological Characteristics and Rhythmic Gymnastics Efficiency of the Physical Education Female Students , Faculty of Physical Education, University of Nis, Serbia, Faculty of Physical Education, University of Pristine- Leposavic (Kosovo) Serbia.

http://www.eufapa.upol.ez/www/EUCAPA2006 /full/popovic1.pdf

21. Sousa, Filipa \& Lebre, Eunice (2010): Biomechanical analysis of two different jumps in Rhythmic Gymnastics

http://w4.ub.unikonstanz.de/cpa/article/view/2154 